\title{
Prognostic role of the preoperative neutrophil-to-lymphocyte ratio and albumin for 30-day mortality in patients with postoperative acute pulmonary embolism
}

Chuan Liu ${ }^{1,2+}$, Hui-lu Zhan ${ }^{1,3+}$, Zhang-Heng Huang ${ }^{1}$, Chuan Hu ${ }^{4}$, Yue-Xin Tong ${ }^{1}$, Zhi-Yi Fan ${ }^{1}$, Meng-Ying Zheng ${ }^{5}$, Cheng-Liang Zhao ${ }^{1 *}$ and Gui-Yun Ma ${ }^{1 *}$

\begin{abstract}
Background: This retrospective study aimed to investigate the prognostic value of the neutrophil-to-lymphocyte ratio (NLR) and albumin for 30-day mortality in patients with postoperative acute pulmonary embolism (PAPE).

Methods: We retrospectively reviewed the medical records of 101 patients with PAPE admitted from September 1, 2012, to March 31, 2019. The characteristics, surgical information, admission examination data and mortality within 30 days after PAPE were obtained from our electronic medical recording system and follow-up. The associations between the NLR, PLR, and other predictors and 30-day mortality were analyzed with univariate and multivariate analyses. Then, the nomogram including the independent predictors was established and evaluated.
\end{abstract}

Results: Twenty-four patients died within 30 days, corresponding to a 30-day mortality rate of $23.8 \%$. The results of the multivariate analysis indicated that both the NLR and albumin were independent predictors for 30-day mortality in patients with PAPE. The probability of death increased by approximately $17.1 \%$ (OR $=1.171,95 \% \mathrm{Cl}: 1.073-1.277$, $P=0.000$ ) with a one-unit increase in the NLR, and the probability of death decreased by approximately $15.4 \%$ $(\mathrm{OR}=0.846,95 \% \mathrm{Cl}: 0.762 \mathrm{c}-0.939, P=0.002)$ with a one-unit increase in albumin. The area under the curve of the nomogram was 0.888 (95\% Cl: 0.812-0.964).

Conclusion: Our findings showed that an elevated NLR and decreased albumin were related to poor prognosis in patients with PAPE. The NLR and albumin were independent prognostic factors for PAPE.

Keywords: Neutrophil-to-lymphocyte ratio, Albumin, Mortality, Postoperative acute pulmonary embolism

\footnotetext{
* Correspondence: 38221965@qq.com; maguiyun3778@163.com

${ }^{+}$Chuan Liu and Hui-lu Zhan contributed equally to this work.

'Department of Orthopedic, Affiliated Hospital of Chengde Medical University, Chengde, China

Full list of author information is available at the end of the article
}

C C The Author(s). 2020 Open Access This article is licensed under a Creative Commons Attribution 4.0 International License, which permits use, sharing, adaptation, distribution and reproduction in any medium or format, as long as you give appropriate credit to the original author(s) and the source, provide a link to the Creative Commons licence, and indicate if changes were made. The images or other third party material in this article are included in the article's Creative Commons licence, unless indicated otherwise in a credit line to the material. If material is not included in the article's Creative Commons licence and your intended use is not permitted by statutory regulation or exceeds the permitted use, you will need to obtain permission directly from the copyright holder. To view a copy of this licence, visit http://creativecommons.org/licenses/by/4.0/. The Creative Commons Public Domain Dedication waiver (http://creativecommons.org/publicdomain/zero/1.0/) applies to the data made available in this article, unless otherwise stated in a credit line to the data. 


\section{Background}

Postoperative acute pulmonary embolism (PAPE) is one of the most dangerous complications following operations, with an incidence between 0.9 and 3.1\% [1-4]. Although the methods of diagnosis and treatment of PAPE have been continuously developed in recent years, including imaging diagnosis, interventional surgery and medicinal chemotherapy, the overall survival rate of patients with PAPE is extremely low. It was reported that the shortterm mortality of patients with PAPE was between 10 and 23.1\% [5-9]. Therefore, identifying the preoperative risk factors associated with mortality may help to direct more aggressive treatment strategies, such as fibrinolytic therapy, towards patients who will derive the greatest benefit.

The mechanism of inflammatory reactions is closely related to the occurrence and development of thromboembolism [10]. In recent years, many researchers have reported that some predictors based on inflammation are associated with prognosis in patients with pulmonary embolism, such as the neutrophil-to-lymphocyte ratio (NLR), monocyte-tolymphocyte ratio (MLR), red blood cell distribution width (RDW), and C-reactive protein (CRP) [11-14]. In addition, the relationship between nutritional status and prognosis in patients with pulmonary embolism has also been extensively studied in a previous study [15]. Plasma albumin is one of the important indicators reflecting systemic nutritional status and is associated with prognosis in patients with acute pulmonary embolism [16]. However, previous studies have focused on nonsurgical patients, and no studies have focused on the relationship between these predictors and mortality in patients with PAPE. Therefore, this study was performed to investigate the relationship of admission NLR, plasma albumin and other predictors with 30-day mortality in patients with PAPE.

\section{Methods}

\section{Patients}

We performed a single-center, retrospective and casecontrol study. The medical records of consecutive patients who were diagnosed with pulmonary embolism from September 1, 2012, to March 31, 2019, in our hospital were reviewed, and patients who were diagnosed with acute pulmonary embolism within 90 days postoperatively were included in this study. In the present study, only patients with pulmonary embolism confirmed by computed tomography pulmonary angiography (CTPA) were defined as pulmonary embolism patients, and patients with suspected but unconfirmed pulmonary embolism by examination were not defined as pulmonary embolism patients. Patients were excluded if they underwent cardiac surgery, did not have complete data, had received blood transfusion within 1 month preoperatively, had comorbid infection, and had comorbid hematological disease or received immunosuppressive therapy within 1 month preoperatively. Finally, 101 patients met our inclusion criteria. All patients with PAPE met the diagnostic criteria of the 2014 ESC guidelines on the diagnosis and management of acute pulmonary embolism [17].

\section{Data collection}

Data were extracted from the hospital electronic database by two independent doctors. If controversial data were encountered, the two doctors who collected the data underwent discussion to reach an agreement. All patients' characteristics (sex, age, BMI, smoking history and drinking history), comorbidities (hypertension, diabetes, respiratory diseases, chronic coronary heart disease, chronic arrhythmia, history of stroke and chronic renal failure), surgical information (surgical type and ASA level), admission examination data (neutrophil-tolymphocyte ratio; platelet-to-lymphocyte ratio; monocyte-to-lymphocyte ratio; hemoglobin; white blood cell; platelet; mean platelet volume; platelet distribution width; red cell distribution width; glucose; neutrophil; lymphocyte; creatinine and albumin) and the situation within 30 days after PAPE were obtained through our electronic medical recording system and follow-up. Complete blood counts (CBCs), blood glucose levels, and albumin assessments were carried out at the biochemistry laboratory of our hospital. The NLR was obtained by dividing the absolute neutrophil counts by the absolute lymphocyte counts from the same blood sample, the PLR was obtained by dividing the absolute platelet counts by the absolute lymphocyte counts from the same blood sample, and the MLR was obtained by dividing the absolute monocyte counts by the absolute lymphocyte counts from the same blood samples. All test results were obtained from the same blood sample test within 3 days before surgery.

\section{Statistical analysis}

Data analysis was performed using the Statistical Package for the Social Sciences version 25.0 for Windows (IBM, Chicago, IL, USA). Data with a normal distribution are represented as the mean \pm standard deviation, and Student's t-test was used to compare two groups. The data with an abnormal distribution are represented as medians (interquartile ranges), and the Mann-Whitney $U$ test was used to compare two groups. Categorical variables are represented as numbers or percentages, and the $\chi^{2}$ test or Fisher's exact test was performed for categorical variables. Based on the univariate analysis, variables with a $P$ value $<0.05$ were included in the multivariate logistic regression analysis to confirm the independent risk factors. Forward logistic regression analysis was conducted to estimate the OR and 95\% CI for 30-day mortality of the NLR, albumin and other parameters after adjusting for potential confounding factors. The receiver operating characteristic 
(ROC) curve was used to examine the performance of independent risk factors in predicting 30-day mortality. The area under the curve (AUC) was derived from the ROC curve, which ranged from 0.5 to 1.0 - with higher values indicating higher discriminatory ability, and the Youden Index (maximum [sensitivity +specificity] minus 1) was adopted to define the optimal cut-off value. Afterwards, a nomogram based on the independent predictors was established, and the calibration curve and decision curve analysis (DCA) were generated to evaluate the nomogram. In addition, the AUC of the nomogram was calculated, and the differences in the AUC between the nomogram and independent predictors were compared by the pROC package in $\mathrm{R}$ software (version 3.6.1). All $P$ values $<0.05$ were accepted as statistically significant.

\section{Results}

Baseline

During the study period, 125 patients were diagnosed with pulmonary embolism within 90 days after noncardiac surgery.
Twenty-four patients were excluded because they did not meet our criteria for hematological disease (2 cases), received blood transfusion within 1 month preoperatively (13 cases), had an infection (2 cases), received immunosuppressive therapy within 1 month preoperatively (1 case) and had missing data (6 cases). Finally, 101 patients with PAPE following noncardiac surgery met our inclusion criteria and were included in this study, which included 41 males and 60 females, and the median age was 64 years (interquartile range: 57.5071.00 years). For 101 patients, the median time of PAPE was 3 days (interquartile range: $1-5$ days). Seven patients were diagnosed with massive pulmonary embolism: ten patients received fibrinolytic therapy, and the remaining patients received anticoagulant therapy. The demographic data and clinical data of deaths and survivors are listed in Table 1.

\section{Prognostic factors of PAPE}

Twenty-four patients died within 30 days, corresponding to a 30 -day mortality rate of $23.8 \%$. There were no significant differences in terms of age, sex, BMI, smoking

Table 1 Comparison of baseline and comorbidities between deaths and survivors

\begin{tabular}{|c|c|c|c|c|}
\hline & Total $(n=101)$ & Deaths $(n=24)$ & Survivors $(n=77)$ & $P$ \\
\hline Age, yr & $64.00(57.50-71.00)^{a}$ & $67.00(59.00-75.75)^{a}$ & $63.00(57.00-70.00)^{a}$ & 0.200 \\
\hline Sex (Female) & 60 & 12 & 48 & 0.283 \\
\hline $\mathrm{BMI}, \mathrm{kg} / \mathrm{m}^{2}$ & $25.85 \pm 3.68$ & $24.54 \pm 4.10$ & $26.31 \pm 3.59$ & 0.050 \\
\hline Smoking history & 23 & 6 & 17 & 0.766 \\
\hline Drinking history & 19 & 4 & 15 & 0.758 \\
\hline Surgical type & & & & 0.861 \\
\hline Musculoskeletal & 45 & 12 & 33 & \\
\hline Abdominal & 28 & 7 & 21 & \\
\hline Respiratory & 10 & 2 & 8 & \\
\hline Gynecologic & 8 & 2 & 6 & \\
\hline Neurosurgery & 5 & 1 & 4 & \\
\hline Vascular & 5 & 0 & 5 & \\
\hline ASA & & & & 0.787 \\
\hline$\|$ & 65 & 16 & 49 & \\
\hline III & 36 & 8 & 28 & \\
\hline Admission SBP & $120.00(135.00,150.00)^{a}$ & $124.50(133.50,149.25)^{a}$ & $120.00(136.00,151.00)^{a}$ & 0.873 \\
\hline \multicolumn{5}{|l|}{ Comorbidities } \\
\hline Hypertension & 38 & 9 & 29 & 0.989 \\
\hline Diabetes & 15 & 2 & 13 & 0.484 \\
\hline Coronary heart disease & 19 & 4 & 15 & 0.993 \\
\hline Respiratory diseases & 9 & 1 & 8 & 0.600 \\
\hline Arrhythmia & 4 & 1 & 3 & $1.000^{b}$ \\
\hline History of stroke & 7 & 2 & 5 & 1.000 \\
\hline Renal failure & 1 & 1 & 0 & $0.238^{\mathrm{b}}$ \\
\hline
\end{tabular}

${ }^{a}$ Interquartile range

${ }^{\mathrm{b}}$ Fisher's Exact test

$B M I$ Body mass index, SBP Systolic blood pressure 
Table 2 Comparison of admission laboratory data between deaths and survivors

\begin{tabular}{llll}
\hline & Deaths $(n=24)^{*}$ & Survivors $(n=77)^{*}$ & $P$ \\
\hline NLR & $14.13(7.67-23.04)$ & $5.93(2.60-8.70)$ & 0.000 \\
PLR & $230.00(102.25-396.24)$ & $157.29(103.99-243.52)$ & 0.193 \\
MLR & $0.80(0.44-1.27)$ & $0.44(0.31-0.77)$ & 0.004 \\
WBC, $\times 10^{9} / L$ & $13.84(8.80-17.47)$ & $9.74(6.62-12.71)$ & 0.001 \\
Neutrophil, $\times 10^{9} / L$ & $12.21(8.04-15.85)$ & $6.20(3.98-9.91)$ & 0.000 \\
Lymphocyte, $\times 10^{9} / L$ & $0.82(0.51-1.59)$ & $1.21(0.90-1.82)$ & 0.017 \\
Monocyte, $\times 10^{9} / L$ & $0.63(0.36-0.89)$ & $0.63(0.45-0.99)$ & 0.621 \\
PLT, $\times 10^{9} / L$ & $163.50(131.25-215.25)$ & $199.00(141.00-247.00)$ & 0.273 \\
MPV, fL & $10.15(9.30-10.78)$ & $10.10(9.40-10.88)$ & 0.631 \\
PDW & $12.75(11.28-15.80)$ & $13.25(10.73-16.08)$ & 0.990 \\
Hb, g/L & $121.00(108.25-141.50)$ & $108.00(90.00-119.00)$ & 0.795 \\
RDW & $13.15(12.73-15.33)$ & $13.20(12.45-14.35)$ & 0.369 \\
Creatinine, $\mu$ mol/L & $84.40(71.72-106.50)$ & $72.00(59.75-87.00)$ & 0.023 \\
GLU, mmol/L & $8.19(6.95-13.83)$ & $7.60(5.56-9.92)$ & 0.054 \\
Albumin, g/L & $32.33(27.37-35.69)$ & $38.20(32.49-45.80)$ & 0.008 \\
\hline
\end{tabular}

*All variables are describe as median and interquartile range

$N L R$ neutrophil-to-lymphocyte ratio, PLR platelet to lymphocyte ratio, WBC white blood cell, MLR monocyte-to-lymphocyte ratio, $P L T$ platelet, MPV mean platelet volume, $P D W$ platelet distribution width, $H b$ hemoglobin, $R D W$ red cell distribution width, GLU glucose

history, drinking history, admission systolic blood pressure, surgical type or ASA level (all $P$ values $>0.05$ ). There were no significant differences in terms of hypertension, diabetes, respiratory diseases, coronary heart disease, arrhythmia, history of stroke or renal failure (all $P$ values $>0.05)$. The baseline characteristics and comorbidities of the patients are shown in Table 1. The preoperative laboratory parameters are presented in Table 2. The NLR, neutrophil count and creatinine level were significantly higher in those who died than in survivors with PAPE (all $P$ values $<0.05$ ), and the albumin level was significantly lower in those who died than in survivors after PAPE $(P=0.008)$. There were no significant differences in the other parameters included in our research (Table 2).

To further confirm the independent risk factors for mortality after PAPE, multivariate logistic analysis was performed. The NLR, MLR, WBC, neutrophil, lymphocyte, creatinine, and albumin (all $P$ values $<0.05$ ) were included in the multivariate analysis, and the results indicated that both the NLR and albumin were independent predictors of 30-day mortality in patients with PAPE. The probability of death increased by approximately $17.1 \%(\mathrm{OR}=1.171,95 \% \mathrm{CI}: 1.073-1.277, P=$ 0.000 ) with a one-unit increase in the NLR, and the probability of death decreased by approximately $15.4 \%$ (OR $=0.846,95 \%$ CI: $0.762 \mathrm{c}-0.939, P=0.002)$ with a one-unit increase in albumin (Table 3). In addition, the results indicated that creatinine, the MLR, neutrophil, lymphocyte and WBC were no longer independent predictors in multivariate analysis (all $P$ values $>0.05$ ).

\section{Development of a nomogram}

Based on the independent predictors, a nomogram was established to predict 30-day mortality in PAPE patients (Fig. 1). The AUC of the nomogram was 0.888 (95\% CI: 0.812-0.964), which was significantly higher than that of any single predictor $(P$ value $<0.05)$ (Table 4 and Figs. 2 and 3a). Moreover, the calibration curve is shown in Fig. $2 \mathrm{~b}$, and the results indicated that the prediction by the nomogram was highly consistent with the actual observations. In addition, the DCA indicated that if the threshold probability of a patient and a doctor was between 5 and 75\%, this nomogram predicted 30-day mortality with more benefit than the scheme(Fig. 2c).

\section{Discussion}

PAPE is one of the most dangerous complications following operations, and it is necessary to predict the prognosis of patients early. To the best of our knowledge, this is the first study to investigate predictors and establish a nomogram of 30-day mortality among patients with PAPE following noncardiac surgery. The primary findings of our study were that the NLR was significantly higher in non-surviving patients than in survivors and that plasma albumin was significantly lower in those who died than in survivors; both the NLR

Table 3 Multivariate regression results of 30-days mortality

\begin{tabular}{lllllll}
\hline & B & SE & Wald & OR & $95 \% \mathrm{Cl}$ & $P$ \\
\hline Albumin & -0.167 & 0.053 & 9.881 & 0.846 & $0.762-0.939$ & 0.002 \\
NLR & 0.158 & 0.044 & 12.644 & 1.171 & $1.073-1.277$ & 0.000
\end{tabular}

NLR neutrophil-to-lymphocyte ratio 


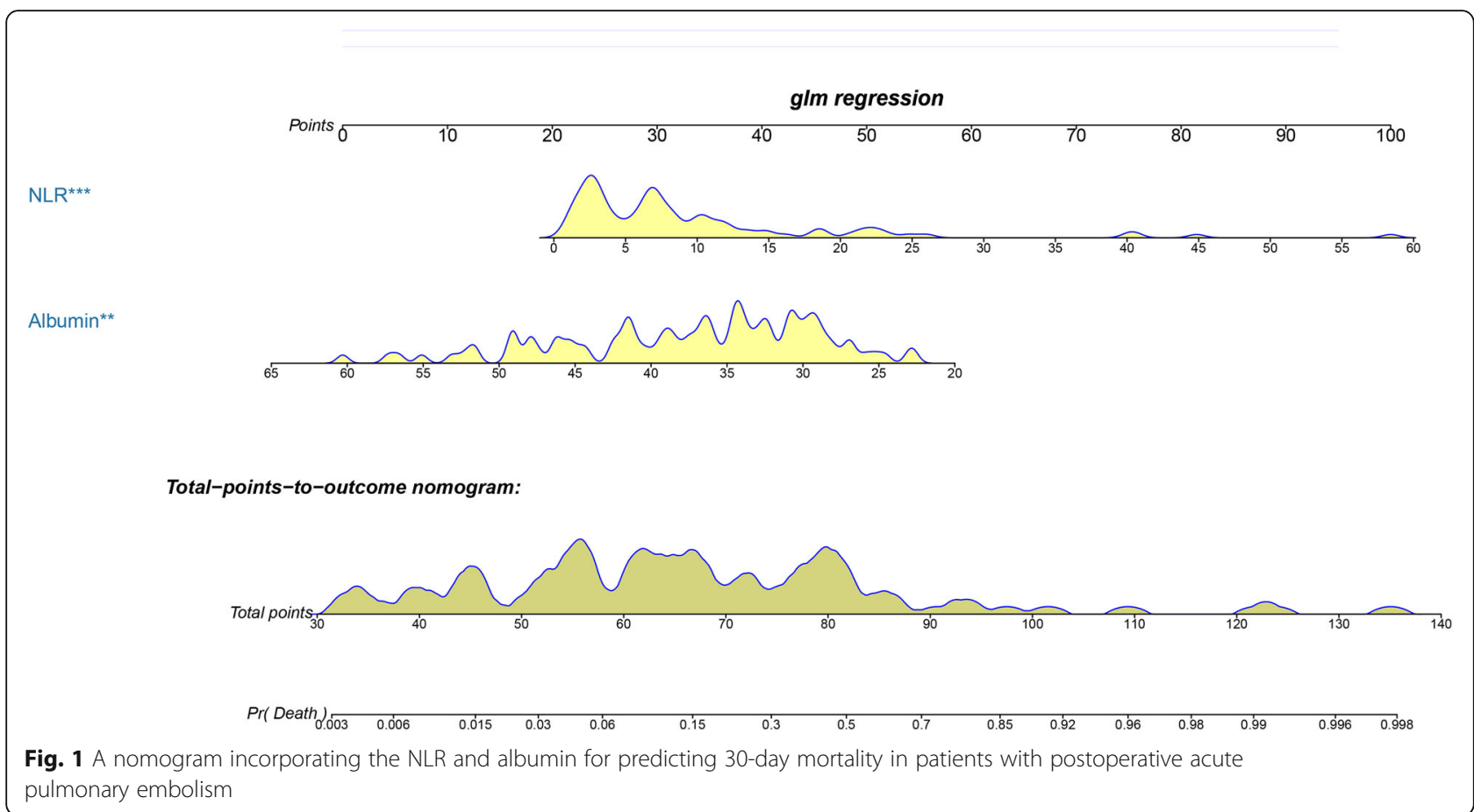

and albumin were independent predictors for 30-day mortality among patients with PAPE following noncardiac surgery. Moreover, the nomogram based on the NLR and albumin showed good performance in predicting 30-day mortality in patients with PAPE.

In our research, 101 patients were included, and 24 patients died within 30 days, corresponding to a 30-day mortality rate of $23.8 \%$. According to previous studies, the mortality rate of APE patients ranges from 8.1$25.3 \%$ [12, 18-20]. Our results showed that the mortality of our cohort was within this range. In our research, the NLR was identified as an effective prognostic biomarker for PAPE patients. The NLR is the comprehensive presentation of systemic inflammation and the balance between neutrophils and lymphocytes in CBCs. Previous studies have shown that an elevated NLR is associated with an increased rate of hospital mortality among patients with acute pulmonary embolism [13], acute exacerbation of chronic obstructive pulmonary disease [21], and acute type A aortic dissection [22]; of 30-day mortality among patients with acute pulmonary embolism [19], acute kidney injury [23], ST-elevation myocardial infarction [24], and intracerebral hemorrhage [25, 26]; and of long-term mortality among patients with ST- elevation myocardial infarction [27], breast cancer [28] and epithelial ovarian cancer [29].

The link between inflammation and pulmonary embolism has been well investigated, although the underlying mechanism is not completely understood. The relationship between them may be linked by cytokines, proinflammatory cytokines, and acute-phase proteins, such as CRP, IL-8, and tumor necrosis factor, which promote the procoagulant state and play an important role in the progression of venous thromboembolism by inducing the expression of tissue factors. In addition, it has recently been reported that inflammatory mediators, such as polyphosphates and bradykinin, can directly activate contact systems and initiate external coagulation pathways [30-32]. In our research, we found that the NLR was an independent predictor of 30-day mortality in patients with PAPE, and the area under the curve of the NLR was 0.823 . Therefore, we concluded that the NLR is a simple and effective prognostic predictor for patients with PAPE.

We also found that albumin was significantly lower in those who died than in survivors. To our knowledge, this is the first study to indicate the relationship between albumin and mortality in patients with PAPE. Albumin is

Table 4 Values of predicators in predicting 30-days mortality

\begin{tabular}{lllllll}
\hline Predicators & AUC & $95 \%$ Cl for AUC & $P$ & Cut-off & Sensitivity & Specificity \\
\hline NLR & 0.823 & $0.729-0.917$ & 0.000 & 12.00 & 0.625 & 0.909 \\
Albumin & 0.768 & $0.668-0.868$ & 0.000 & 36.66 & 0.571 & 0.875 \\
\hline
\end{tabular}

AUC area under the curve, NLR neutrophil-to-lymphocyte ratio 

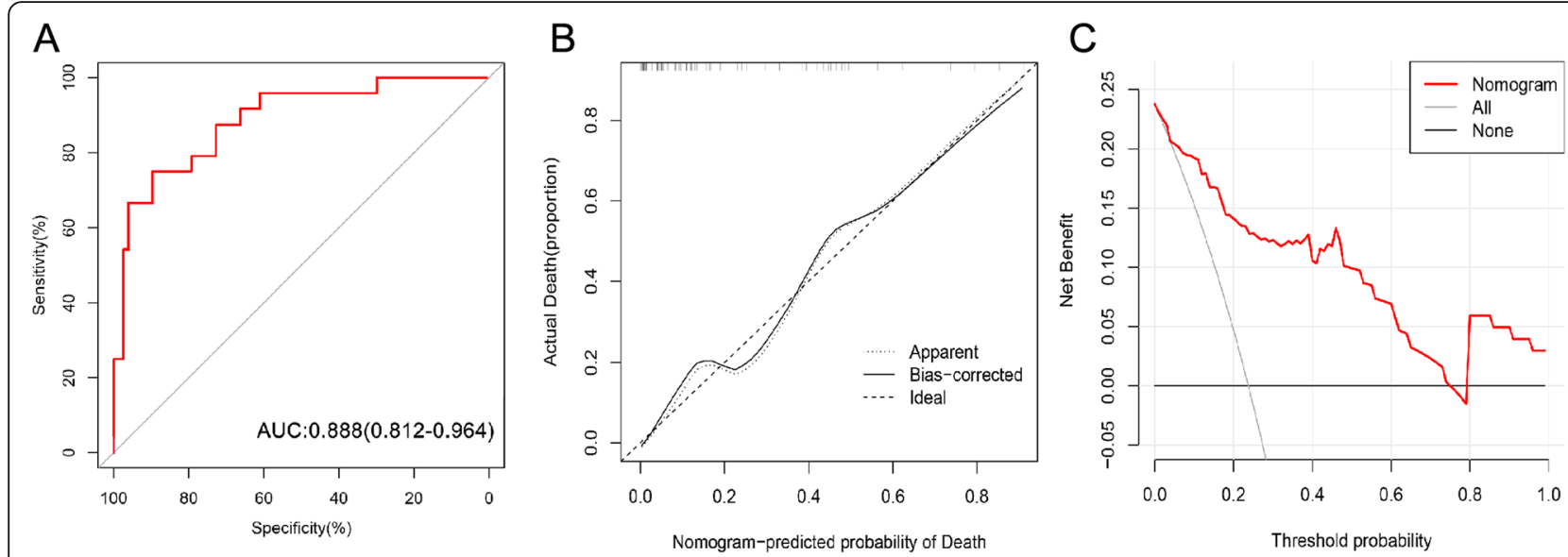

Fig. 2 Receiver operating characteristic curve, calibration curve, and decision curve analysis of the nomogram. $\mathbf{a}$. The area under the receiver operating characteristic curve was 0.888 (95\% Cl: 0.812-0.964); b. The calibration curve showed that the nomogram-predicted probability of death was highly consistent with the actual probability of death; $\mathbf{c}$. The decision curve analysis indicated that if the threshold probability of a patient and a doctor was between 5 and 75\%, this nomogram predicted 30-day mortality with more benefit than the scheme

an indicator of the nutritional status of patients and can regulate the anticoagulation system to some extent. Hypoproteinemia has been confirmed to be associated with mortality in patients with acute pulmonary embolism in previous studies [16]. In a previous study, the mechanism of the association between albumin and mortality was partly explained. Plasma albumin can interact with NO to some extent and generate S-nitrosoproteins, which then promote vasomotor activity and inhibit platelet aggregation.
When albumin levels drop, the effect will be weakened [33, 34]. In addition, plasma albumin has important antioxidant, anti-inflammatory and drug carrier effects in human physiological functions [35]. Therefore, a lower plasma albumin concentration will inevitably lead to a decrease or loss of these effects.

There were also some limitations in our research. First, as a single-center study, only 101 patients met the criteria and were included in our study, which was a
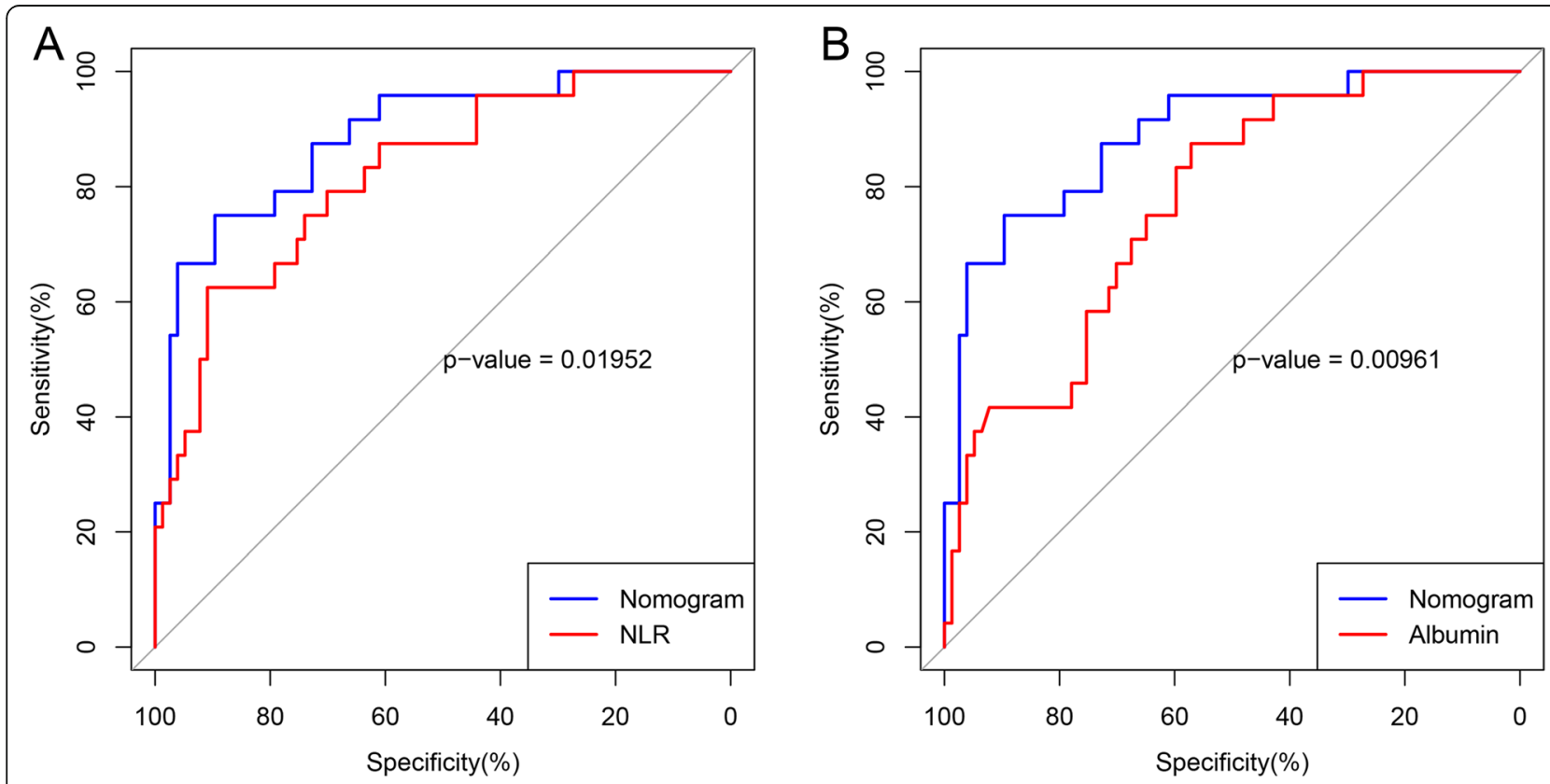

Fig. 3 Receiver operating characteristic curve of the nomogram, the NLR, and albumin. a. The area under the receiver operating characteristic curve of the nomogram was significantly higher than the area under the receiver operating characteristic curve of the NLR. $\mathbf{b}$. The area under the receiver operating characteristic curve of the nomogram was significantly higher than the area under the receiver operating characteristic curve of albumin 
small sample size. The small sample size makes it impossible to classify and discuss patients with PAPE for specific operations, such as arthroplasty and gastrointestinal cancer resection. Second, although the nomogram showed good performance in terms of the AUC, calibration curve and DCA, independent validation is needed. Finally, as a retrospective study, our research had its own limitations, and some potential predictors were not included in our research. We hope that multicenter and prospective research can be performed to confirm our conclusion in the future.

\section{Conclusions}

Both the NLR and albumin were independent predicators for 30-day mortality among patients with acute pulmonary embolism following noncardiac surgery, and the NLR and albumin were better predictors together than separately. This enables assessing the severity of PAPE and can guide the clinical management of PAPE.

\begin{abstract}
Abbreviations
PAPE: Postoperative acute pulmonary embolism; NLR: Neutrophil-tolymphocyte ratio; MLR: Monocyte-to-lymphocyte ratio; RDW: Red blood cell distribution width; CRP: C-reactive proteinl; CBC: Complete blood count; ROC: Receiver operating characteristic curveAUCArea under the curve; DCA: Decision curve analysis; LMR: Lymphocyte to monocyte ratio
\end{abstract}

\section{Acknowledgements}

We would like to thank all the staff in Department of Orthopaedic, Affiliated Hospital of Chengde Medical University for their contribution on our research.

\section{Authors' contributions}

$\mathrm{CL}, \mathrm{CLZ}, \mathrm{CH}, \mathrm{HLZ}$, and ZHH made substantial contributions to the design of this study; $C L, C H, M Y Z, C L Z$, and $Y X T$ collected and analyzed the data; $C L$, ZYF, and GYM wrote the manuscript; CLZ and GYM revised the manuscript. All authors read and approved the final manuscript.

\section{Funding}

We received no external funding for this study.

\section{Availability of data and materials}

The datasets generated during and/or analyzed during the current study are available from the corresponding author on reasonable request.

\section{Ethics approval and consent to participate}

This study was approved by the Institutional Review Board of Affiliated Hospital of Chengde Medical University. Written informed consent was obtained from all patients. No children (under 16 years old) were included in this study.

\section{Consent for publication}

Not applicable.

\section{Competing interests}

All authors declare that they have no competing interests.

\section{Author details}

'Department of Orthopedic, Affiliated Hospital of Chengde Medical University, Chengde, China. ${ }^{2}$ Graduate School of China Medical University, Shenyang, China. ${ }^{3}$ School and Hospital of Stomatology, Wenzhou Medical University, Wenzhou, China. ${ }^{4}$ Qingdao University medical college, Qingdao, China. ${ }^{5}$ Second Clinical Medical College of Wenzhou Medical University, Wenzhou, China
Received: 4 January 2020 Accepted: 15 June 2020

Published online: 24 June 2020

\section{References}

1. Rinaldo L, Brown DA, Bhargav AG, Rusheen AE, Naylor RM, Gilder HE, Monie DD, Youssef SJ, Parney IF. Venous thromboembolic events in patients undergoing craniotomy for tumor resection: incidence, predictors, and review of literature. J Neurosurg. 2019:1-12.

2. De la Garza RR, Longo M, Gelfand Y, Echt M, Kinon MD, Yassari R. Timing of prophylactic anticoagulation and its effect on thromboembolic events after surgery for metastatic tumors of the spine. Spine. 2019:44(11):E650-e655.

3. Rottenstreich A, Kleinstern G, Spectre G, Da'as N, Ziv E, Kalish Y. Thromboembolic events following Splenectomy: risk factors, prevention, management and outcomes. World J Surg. 2018;42(3):675-81.

4. Goel R, Fleischman AN, Tan T, Sterbis E, Huang R, Higuera C, Parvizi J, Rothman $\mathrm{RH}$. Venous thromboembolic prophylaxis after simultaneous bilateral total knee arthroplasty: aspirin versus warfarin. Bone Joint J. 2018; 100-b(1 Supple A):68-75.

5. Hoefnagel D, Kwee LE, van Putten EH, Kros JM, Dirven CM, Dammers R. The incidence of postoperative thromboembolic complications following surgical resection of intracranial meningioma. A retrospective study of a large single center patient cohort. Clin Neurol Neurosurg. 2014;123:150-4.

6. Mantziari S, Gronnier C, Pasquer A, Gagniere J, Thereaux J, Demartines N, Schafer M, Mariette $\mathrm{C}$. Incidence and risk factors related to symptomatic venous thromboembolic events after Esophagectomy for Cancer. Ann Thorac Surg. 2016;102(3):979-84.

7. Chen RX, Wang HZ, Dong J, Ren H, Chen XJ, Xu JX, Yang Y, Wang GD. Pulmonary embolism in non-brain tumor patients after surgery-a retrospective study in China. World J Surg Oncol. 2017;15(1):22.

8. Li YP, Shen L, Huang W, Hu XF, Xie D, Yang J, Song X, Zhao YF, Zhou CJ, Jiang GN. Prevalence and risk factors of acute pulmonary embolism in patients with lung Cancer surgery. Semin Thromb Hemost. 2018;44(4):33440.

9. Jia J, Xue SM, Xu N. Efficacy of rivaroxaban for pulmonary embolism. Medicine. 2019:98(16):e15224.

10. Branchford BR, Carpenter SL. The role of inflammation in venous thromboembolism. Front Pediatr. 2018;6:142.

11. Jurin I, Trkulja V, Ajduk M, Letilovic T, Hadzibegovic I. Red cell distribution width in acute pulmonary embolism patients: a simple aid for improvement of the 30-day mortality risk stratification based on the pulmonary embolism severity index. Heart Lung. 2019;48(5):436-45.

12. Ertem AG, Yayla C, Acar B, Kirbas O, Unal S, Uzel Sener M, Akboga MK, Efe $\mathrm{TH}$, Sivri S, Sen $\mathrm{F}$, et al. Relation between lymphocyte to monocyte ratio and short-term mortality in patients with acute pulmonary embolism. Clin Respir J. 2018;12(2):580-6.

13. Soylu K, Gedikli O, Eksi A, Avcioglu Y, Soylu Al, Yuksel S, Gulel O, Yilmaz O. Neutrophil-to-lymphocyte ratio for the assessment of hospital mortality in patients with acute pulmonary embolism. Arch Med Sci. 2016;12(1):95-100.

14. Araz O, Yilmazel Ucar E, Yalcin A, Kelercioglu N, Meral M, Gorguner AM, Akgun M. Predictive value of serum Hs-CRP levels for outcomes of pulmonary embolism. Clin Respir J. 2016;10(2):163-7.

15. Hayıroğlu Mi, Keskin M, Keskin T, Uzun AO, Altay S, Kaya A, Öz A, Çinier G, Güvenç TS, Kozan Ö. A novel independent survival predictor in pulmonary embolism: prognostic nutritional index. Clin Appl Thromb Hemost. 2018; 24(4):633-9.

16. Hoskin S, Chow V, Kritharides L, Ng ACC. Incidence and Impact of Hypoalbuminaemia on Outcomes Following Acute Pulmonary Embolism. Heart Lung Circ. 2019;29(2):280-7.

17. Zamorano JL, Achenbach S, Baumgartner H, Bax JJ, Bueno H, Dean V, Deaton C, Erol C, Fagard R, Ferrari R. 2014 ESC guidelines on the diagnosis and management of acute pulmonary embolismThe task force for the diagnosis and Management of Acute Pulmonary Embolism of the European Society of Cardiology (ESC)endorsed by the European Respiratory Society (ERS). Eur Heart J. 2014;21(16):1301-36.

18. Comfere TB, Sprung J, Case KA, Dye PT, Johnson JL, Hall BA, Schroeder DR, Hanson AC, Marienau ME, Warner DO. Predictors of mortality following symptomatic pulmonary embolism in patients undergoing noncardiac surgery. Can J Anesth. 2007;54(8):634-41.

19. Ma Y, Mao Y, He X, Sun Y, Huang S, Qiu J. The values of neutrophil to lymphocyte ratio and platelet to lymphocyte ratio in predicting 30day 
mortality in patients with acute pulmonary embolism. BMC Cardiovasc Disord. 2016;16(1):1-6.

20. Akgüllü Ç, Ömürlü IK, Eryllmaz U, Avcil M, Dağtekin E, Akdeniz M, Güngör H, Zencir C. Predictors of early death in patients with acute pulmonary embolism. Am J Emerg Med. 2015;33(2):214-21..

21. Yao CY, Liu XL, Tang Z. Prognostic role of neutrophil-lymphocyte ratio and platelet-lymphocyte ratio for hospital mortality in patients with AECOPD. Int J Chron Obstruct Pulmon Dis. 2017;12:2285-90.

22. Karakoyun S, Gursoy MO, Akgun T, Ocal L, Kalcik M, Yesin M, Erdogan E, Kulahcioglu S, Bakal RB, Koksal C, et al. Neutrophil-lymphocyte ratio may predict in-hospital mortality in patients with acute type a aortic dissection. Herz. 2015;40(4):716-21.

23. Lai FL, Jun WY, Jin NC, He CY, Xia SH. Neutrophil-lymphocyte ratio is associated with all-cause mortality among critically ill patients with acute kidney injury. Clinica Chimica Acta. 2019;490(NA ):207-13. https://doi.org/10. 1016/j.cca.2018.09.014.

24. Park JS, Seo KW, Choi BJ, Choi SY, Yoon MH, Hwang GS, Tahk SJ, Shin JH. Importance of prognostic value of neutrophil to lymphocyte ratio in patients with ST-elevation myocardial infarction. Medicine. 2018;97(48): e13471..

25. Fei W, Li W, Jiang TT, Xia JJ, Feng $X$, Shen L, Kang WH, Yong D, Mei LX, Ju XF. Neutrophil-to-lymphocyte ratio is an independent predictor of 30-day mortality of Intracerebral hemorrhage patients: a validation cohort study. Neurotox Res. 2018:1-6.

26. Wang F, Xu F, Quan Y, Wang L, Xia JJ, Jiang TT, Shen LJ, Kang WH, Ding Y, Mei LX. Early increase of neutrophil-to-lymphocyte ratio predicts 30-day mortality in patients with spontaneous intracerebral hemorrhage. Cns Neurosci Ther. 2018;25(1):30-5.

27. Arbel Y, Shacham Y, Ziv-Baran T, Perl ML, Finkelstein A, Halkin A, Revivo M, Milwidsky A, Berliner S, Herz I. Higher neutrophil/lymphocyte ratio is related to lower ejection fraction and higher Long-term all-cause mortality in STelevation myocardial infarction patients. Can J Cardiol. 2014;30(10):1177-82.

28. Azab B, Shah N, Radbel J, Tan P, Bhatt V, Vonfrolio S, Habeshy A, Picon A, Bloom S. Pretreatment neutrophi//ymphocyte ratio is superior to platelet/ lymphocyte ratio as a predictor of long-term mortality in breast cancer patients. Med Oncol. 2013;30(1):432.

29. Zhou M, Li L, Wang X, Wang C, Wang D. Neutrophil-to-lymphocyte ratio and platelet count predict Long-term outcome of stage IIIC epithelial ovarian Cancer. Cell Physiol Biochem. 2018:46(1):178-86.

30. Long AT, Kenne E, Jung R, Fuchs TA, Renne T. Contact system revisited: an interface between inflammation, coagulation, and innate immunity. J Thromb Haemost. 2016;14(3):427-37.

31. van Montfoort ML, Meijers JC. Recent insights into the role of the contact pathway in thrombo-inflammatory disorders. Hematol Am Soc Hematol Educ Program. 2014;2014(1):60-5.

32. Wu Y. Contact pathway of coagulation and inflammation. Thromb J. 2015; 13:17.

33. Fanali G, di Masi A, Trezza V, Marino M, Fasano M, Ascenzi P. Human serum albumin: from bench to bedside. Mol Asp Med. 2012;33(3):209-90.

34. Caraceni P, Domenicali M, Tovoli A, Napoli L, Ricci CS, Tufoni M, Bernardi M. Clinical indications for the albumin use: still a controversial issue. Eur 」 Intern Med. 2013;24(8):721-8.

35. Arroyo V, Garcia-Martinez R, Salvatella X. Human serum albumin, systemic inflammation, and cirrhosis. J Hepatol. 2014;61 (2):396-407.

\section{Publisher's Note}

Springer Nature remains neutral with regard to jurisdictional claims in published maps and institutional affiliations.

Ready to submit your research? Choose BMC and benefit from:

- fast, convenient online submission

- thorough peer review by experienced researchers in your field

- rapid publication on acceptance

- support for research data, including large and complex data types

- gold Open Access which fosters wider collaboration and increased citations

- maximum visibility for your research: over $100 \mathrm{M}$ website views per year

At BMC, research is always in progress.

Learn more biomedcentral.com/submissions 